\title{
The Inspiration of Astronomical Phenomena
}

\section{Chris Impey}

Abstract. This paper is an overview of the diverse ways in which the phenomena of astronomy have penetrated and enriched culture (e.g. the pumpernickel in a loaf of marble rye). Humans have always been able to keep the universe in their heads, but that universe has grown from the proximate, sheltering canopy of stars to a vast panoply of planets, stars, galaxies and cosmic cataclysms. These phenomena have inspired and insinuated themselves into the humanities, literature, the visual and performing arts and new forms of expression made possible by computers and the Internet. This multimedia tour attempts to recapitulate and encapsulate the INSAP concept.

\section{Introduction}

This eponymous article tackles the tricky task of encapsulating and setting the stage for the seventh in a series of meetings of uncommon scope and ambition. Starting in 1994, a conference on The Inspiration of Astronomical Phenomena, abbreviated as INSAP, has been held every couple of years at locations scattered around the western world. Almost uniquely in the scholarly arena, the meetings bring together scientists, humanists, historians, philosophers, artists, and diverse thinkers for an examination of the impact on humanity and human culture of the phenomena of the sky.

INSAP had its genesis in a conversation between Ray White, George Coyne, S.J., and Rolf Sinclair over morning coffee in Tucson. Ray was a colleague and mentor of mine at the University of Arizona who, unfortunately, died in 2004, and George and Rolf have since retired from positions as Director of the Vatican Observatory and Programme Officer at the National Science Foundation respectively. They were discussing Isaac Asimov's seminal short story 'Nightfall' and noted that there had never been a concerted academic treatment of the interplay between perceptions of the day-and night-time sky and human culture.

\footnotetext{
${ }^{1}$ Isaac Asimov, 'Nightfall', Astounding Science Fiction, September 1941.

Chris Impey, 'The Inspiration of Astronomical Phenomena', ed. Nicholas Campion and Rolf Sinclair, Culture and Cosmos, Vol. 16 no 1 and 2, 2012, pp. 5-17. www.CultureAndCosmos.org
} 


\section{The Inspiration of Astronomical Phenomena}

'Nightfall's theme is 'what would happen if the stars only came out once every thousand years?' In particular, there had never been a conference to gather interdisciplinary scholars with an interest in astronomy and the sky and foster their interactions.

Ray, George and Rolf set out to rectify that omission. The result has been a series of international conferences that are very well attended, intellectually vibrant, and largely self-supporting. Attendance is generally limited to about a hundred people, to allow for a large amount of interaction. An INSAP meeting typically has invited or keynote presentations, contributed papers and posters, and it might, in addition, include art exhibitions and musical performances. Others attend as observers and do not give formal presentations.

It was clear to the organizers that many interdisciplinary scholars risk neglect, incomprehension, and worse as they deviate from the wellploughed furrows of their fields. An art historian who investigates depictions of the night sky in the Renaissance, or an astronomer who studies sky myths from the South Pacific, is likely to have nobody local to talk to and little reinforcement for their ideas. The collegiality of INSAP is an elixir to most of the attendees. The meetings have all been held in locations with astronomically inspiring sites nearby, and they have been enlivened with field trips, live performances, and public talks.

I claim no special expertise to survey the remarkable breadth of INSAP over the years, but through persistence and luck I've managed to attend and give talks at each of the meetings. What follows will be a whimsical tour of the venues, using historical and cultural ideas as connective tissue.

Figure 1 shows the instigators of INSAP, with apologies to the author. ${ }^{2}$ The late, lamented Ray White is cast as Porthos, perhaps fittingly a 'black' musketeer, whose significant girth identified him as a bon vivant. Porthos is known to enjoy wine, women, and song. Rolf Sinclair is cast as Athos, a father figure who is noble, handsome, and somewhat fond of drink. George Coyne is Aramis, and if we elide over the fictional character's much transgressed vow of celibacy, the fit isn't bad. Aramis is, above all, a loyal friend, and he eventually ascends to the post of Superior General of the Jesuits. Adding a fourth to this founding triumvirate is presumptuous and arbitrary, but I have chosen to cast John David Mooney as the hot-headed D'Artagnan, who eventually matures into a respected leader.

\footnotetext{
${ }^{2}$ Alexander Dumas, The Three Musketeers (London: Puffin Books, 1986).
} 


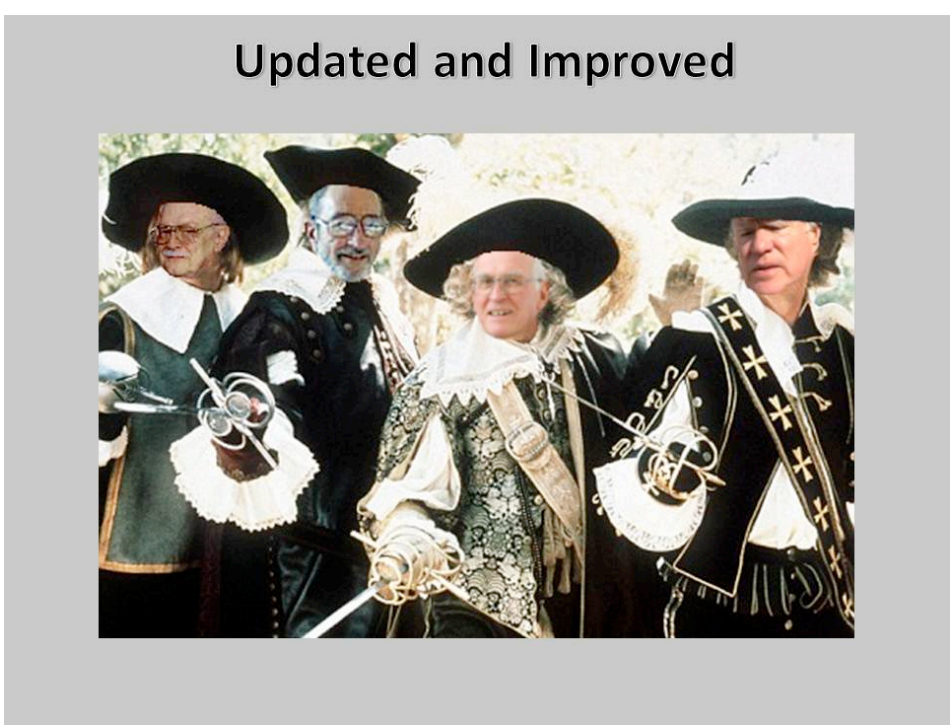

Figure 1. The inspiration for the Inspiration of Astronomical Phenomena was the triumvirate (from left to right) of Ray White, Rolf Sinclair, and George Coyne, S.J., with help from 'honorary musketeer' John David Mooney (far right).

INSAP VII is an appropriate event for a retrospective because the number seven epitomizes the coupling between astronomy and the history of human culture. The cycles of time-day, week, month, and year-are all set by astronomical rhythms, but only the week involves a choice that emerges from culture. Weeks of varying length have been used by different civilizations. The imperial calendar of the late Roman Empire grew to define civic affairs around the world. In all Latin-based languages, the days correspond to the seven celestial objects visible to the naked eye that move among the fixed pattern of the stars: Sun, Moon, Mercury, Venus, Mar, Jupiter, and Saturn. ${ }^{3}$

Seven permeates Western civilization, from wonders of the ancient world and the liberal arts of the trivium and the quadrivium, to its presence in the popular culture with 7-Up and 007 James Bond. Biblical references abound, in the number of days of creation and Passover, deadly sins and virtues, acts of mercy, sorrows of the Virgin Mary, gifts of the Holy Spirit, and horsemen of the Apocalypse. Islam is similarly

\footnotetext{
${ }^{3}$ E.G. Richards, Mapping Time: The Calendar and its History (Oxford: Oxford University Press, 1998).
} 


\section{The Inspiration of Astronomical Phenomena}

pervaded by the number, with seven levels of both heaven and hell, seven layers of the Earth and sky, and a pilgrimage consisting of seven circumambulations of the Kaaba in Mecca.

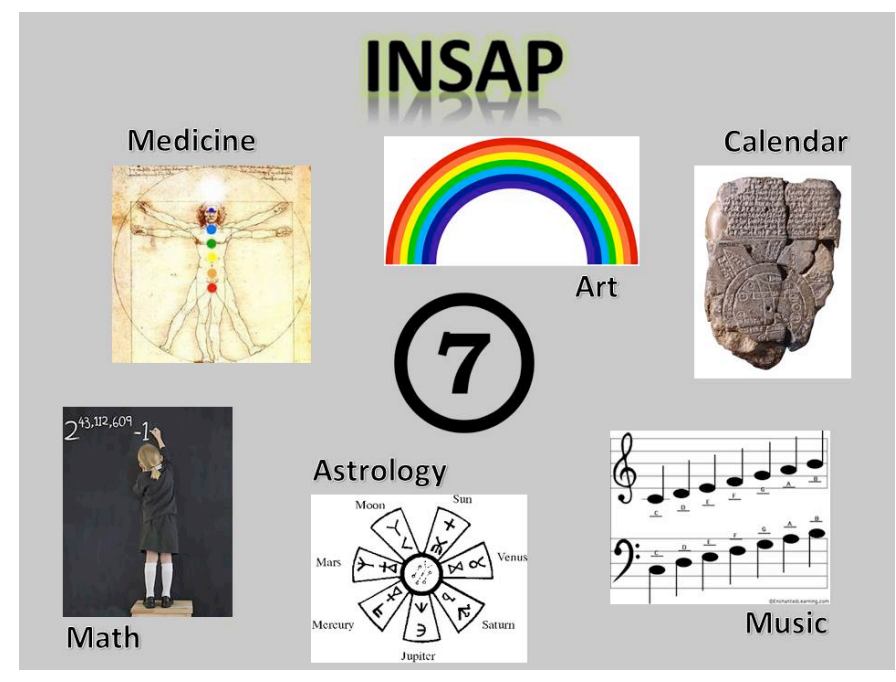

Figure 2. The seventh INSAP provides a fitting occasion to reflect on the way that number resonates in mathematics, music, art, medicine, and the cycles of time that govern human affairs.

The visible spectrum has been divided into seven colours since the time of Newton, Western music uses a diatonic scale, and the seven chakras from Hindu tradition constitute the world's oldest coherent system to describe physical and spiritual well-being. In mathematics, seven sets the first regular-sided figure, the heptagon, which cannot be constructed with just a compass and a straight edge. Seven is also a prime, a factorial prime, a lucky prime, a safe prime, a Mersenne prime, a double Mersenne prime, a happy number, and the lowest number that cannot be represented as the sum of the squares of three integers. ${ }^{4}$ Mundane and mystical, seven surrounds us like an amniotic fluid.

\section{INSAP I}

The first meeting had four themes: the influence of astronomical phenomena on art, literature, myth and religion, and history. In general,

${ }^{4}$ T. Pappas, The Joy of Mathematics: Discovering Mathematics All Around You (San Carlos, CA: World Wide Publishing, 1989). 
specialist sub-disciplines such as Ethnoastronomy and Archaeoastronomy are better handled by conferences with a tighter focus, such as the series of 'Oxford' International Symposia on Archaeoastronomy, and volumes resulting from the meetings of SEAC, the European Society for Astronomy in Culture. ${ }^{5}$ The first INSAP meeting was organized spontaneously and on short notice and attracted mostly astronomers. George Coyne graciously offered his facilities in Castel Gandolfo, Italy, and attendees were housed across the lake in the tranquil and monastic surroundings of the Mondo Migliore retreat. ${ }^{6}$

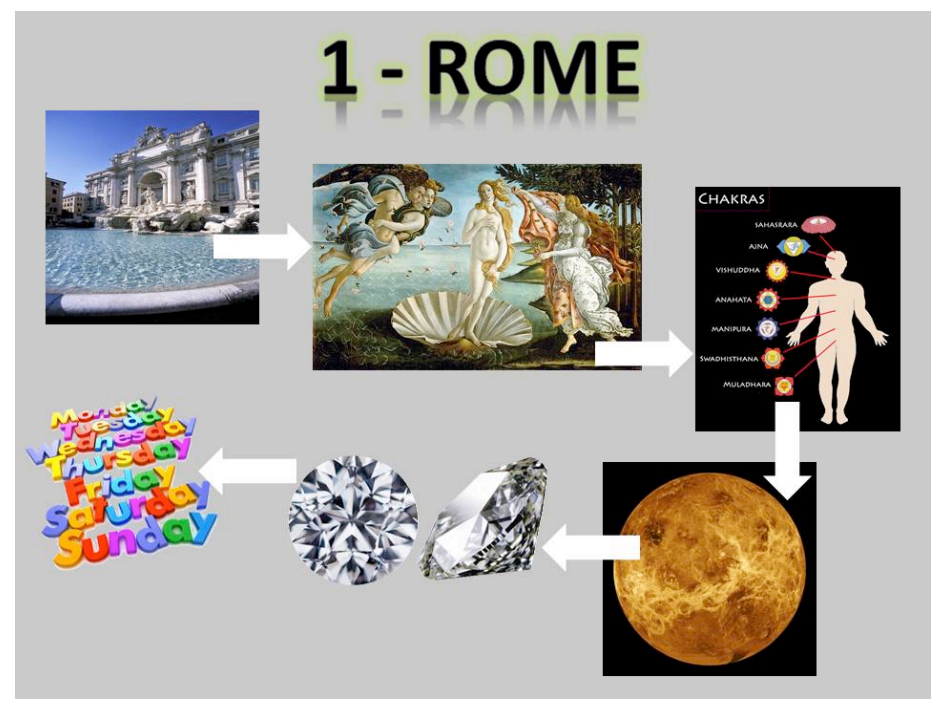

Figure 3. The first INSAP meeting was held at Castel Gandolfo, Italy, in 1994.

The cradle of INSAP and of Western civilization was Rome. In parsing the seven celestial objects that give their names to the days of the week, the natural match to INSAP I is Rome, the epicentre of love and romance. Aphrodite emerges from an act of 'tough love' when Cronos

\footnotetext{
${ }^{5}$ For example, from the Oxford Conferences, J. Fountain, and Rolf Sinclair (eds.), Current Studies in Archaeoastronomy: Conversations Across Space and Time (Durham, NC: Carolina Academic Press, 2005), and from SEAC, J. Vaiskunas, Astronomy and Cosmology in Folk Traditions and Cultural Heritage (Klaipeda, Lithuania: Klaipeda University Press, 2009).

${ }^{6}$ INSAP I, Vistas in Astronomy, Volume 39, Part 4 (1995); INSAP I, Leonardo, Volume 29, Number 2 (1996).
} 
cuts off the genitals of Uranus and throws them into the sea; the goddess grows from the sea foam. By Roman times the goddess has been named after Venus, another back-handed swipe at love given that Earth's sister planet is a 900-degree inferno with swirling clouds of ammonia and sulphuric acid and a surface where lead would melt. Venus maps to the sacral chakra and is a magnificent sight at its maximum elongation in the twilight sky, when it shimmers like a diamond.

\section{INSAP II}

The first meeting was successful but was organized 'on the fly', so did not attract the breadth of participants that would later become the norm. INSAP II was held at the crossroads of the Mediterranean on the island of Malta. The island is home to the oldest megalithic structures with astronomical alignments in the world, dating to the $4^{\text {th }}$ millennium B.C. Attendees visited these temples, seven of which are UNESCO World Heritage sites. ${ }^{7}$

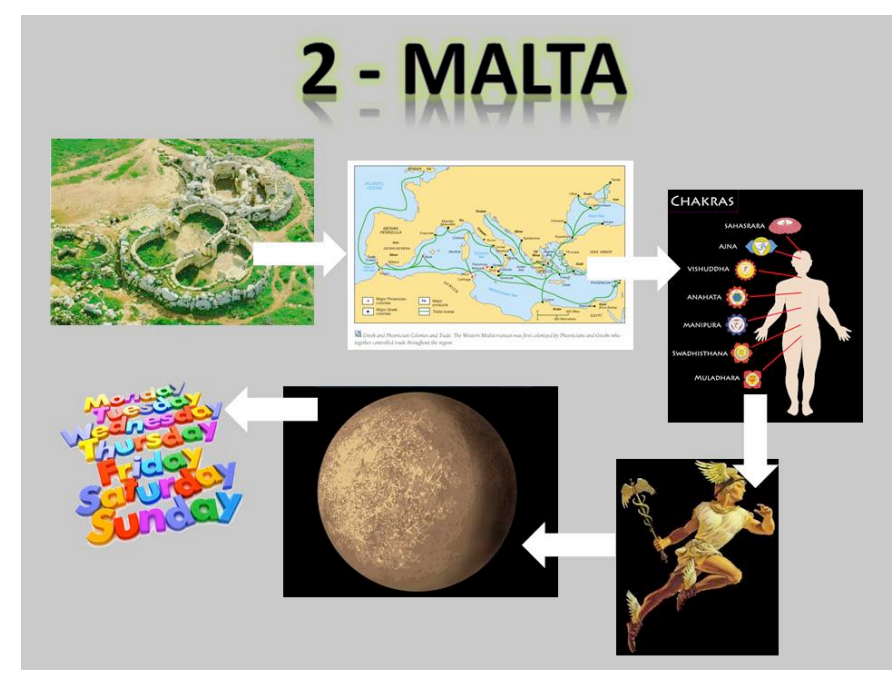

Figure 4. The second INSAP meeting was held on the island of Malta in 1999.

The striking setting at a hotel on the rocky coast fuelled rich discussions in the conference venue, and later on through the evenings over wine and octopus in local taverns. Lynda Williams, the 'Physics Chanteuse', gave

${ }^{7}$ D. Trump, et al., Malta Before History (Valletta, Malta: Miranda, 2004). 
an impromptu and highly entertaining concert in the hotel lounge. With more lead time for advertising, attendance was higher than for the first meeting and more disciplines were represented.

Malta has been a thoroughfare of trade for major civilizations for five millennia. Naturally, in the INSAP pantheon it is associated with the Greek god Hermes, who represented travellers, commerce, and boundaries. Hermes became Mercury in the Roman tradition. Appropriately, the closest planet to the Sun is tied to the meeting closest to the equator so far. Situated at a place where the Mediterranean narrows, Malta is linked to the throat chakra.

\section{INSAP III}

The third conference had auspicious timing, opening on the first day of 2001, the two hundredth anniversary of the discovery of the first asteroid by Guiseppe Piazzi at the Palermo Observatory in Sicily. Ceres was named after the Roman patron goddess of Sicily. The meeting was held partly in the sumptuous settings of the Palazzo dei Normani and the Palazzo Steri, and partly in nearby Valetta. INSAP continued to build momentum for its unique concept, with more attendees and an even larger range of disciplines. The middle day of the meeting was set aside for visits to Greek, Roman, Arabic and Norman sites. The ability of INSAP to bridge art and science was epitomized by the three day exhibition 'Star Dancers', held alongside the conference, where the Bay Area sculptor Daniel Oberti displayed sculptures inspired by his collaboration with the astronomer Maria Sundin from the Stockholm Observatory. Daniel was an INSAP stalwart and is sorely missed since is death in $2009 .{ }^{8}$

Sicily and INSAP III are aligned with the Greek god Ares, bringer of slaughter and war, and his Roman equivalent. Ares is also the god of agriculture, and Sicily is an island with dense and fertile volcanic soil. But it has also been at the epicentre of conquest, most notably in the Peloponnesian War and the epic Punic Wars between the Greeks and the Romans. After the fall of Rome in 440 A.D., Sicily was sacked by the Vandals, the Goths, and the Byzantine Empire in quick succession, and then fell into Arab hands near the turn of the millennium. Under Norman rule in the twelfth century, Sicily was as wealthy as England. The more recent stain of Mafia violence doesn't obscure the fact that this is a

\footnotetext{
${ }^{8}$ Salvatore Serio (ed.), Proceedings of the INSAP III Conference, Memoire della Societa Astronomica Italiana, 2002, Special number 1, Pisa: Istituti Editorialle Poligrafici Internazionale and the Societa Astronomica Italiana.
}

Culture and Cosmos 
vibrant and culturally rich autonomous region of Italy. Reassuringly, most of the volcanoes on Mars and Sicily are ancient and inactive.

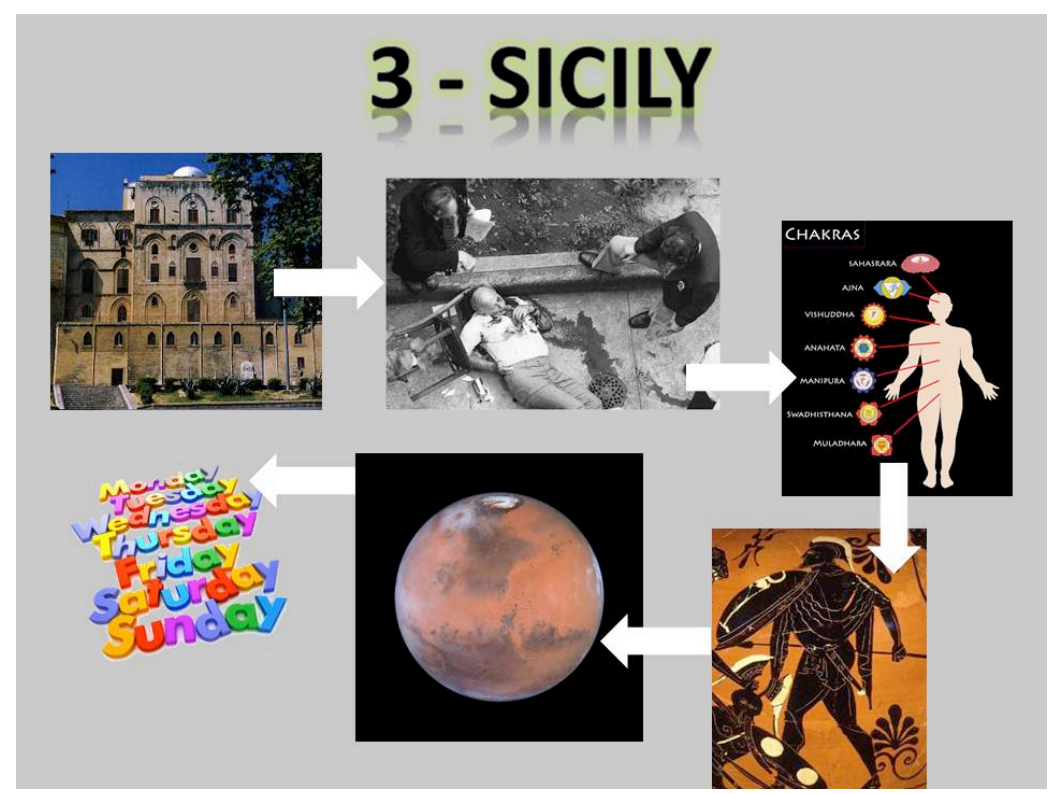

Figure 5. The third INSAP was held on the island of Sicily, Italy, in 2001.

\section{INSAP IV}

The next meeting broke with tradition by moving out of the Mediterranean region to Oxford. However, it kept up the strong link to history by being held at Magdalen College, founded in 1458 and situated in beautiful park land on the banks of the Cherwell River. INSAP IV crossed an important threshold - the astronomical representation was strong, but for the first time most of the presentations were in the arts and the humanities. A special exhibit of work by attending artists was held at the Oxford University Museum, and there was a memorable conference banquet in the same medieval panelled hall where Oscar Wilde, John Betjeman, and Erwin Schrodinger once dined. ${ }^{9}$ Participants were treated

\footnotetext{
9 Nicholas Campion (ed.), The Inspiration of Astronomical Phenomena, Proceedings of the Fourth Conference on the Inspiration of Astronomical Phenomena, Magdalen College, Oxford, 3-9 August 2003, Culture and Cosmos, Vol 8, no 1 and 2, 2004.
} 
to a closed-access, dawn tour of Stonehenge and then nearby Avebury, evidence of the profound way that astronomy was incorporated into Bronze Age life. ${ }^{10}$ It was not held on the pivotal occasion of 21 June but that was good planning, since the monument is transformed into a crowded circus by modern day pagans every summer solstice.

Assignation of the fourth INSAP to a celestial object is easy; Stonehenge marks the primacy of Sun worship, with its modern echo in the clockwise movement of the hands of a watch. Helios, the Sun god, rides his chariot in an arc across the sky every day. The clever trick of the Romans was to co-opt many pagan traditions and gain adherents to Christianity with less resistance. The Gregorian calendar incorporates some of these sleights of hand; designating Sunday as the day of worship is another.

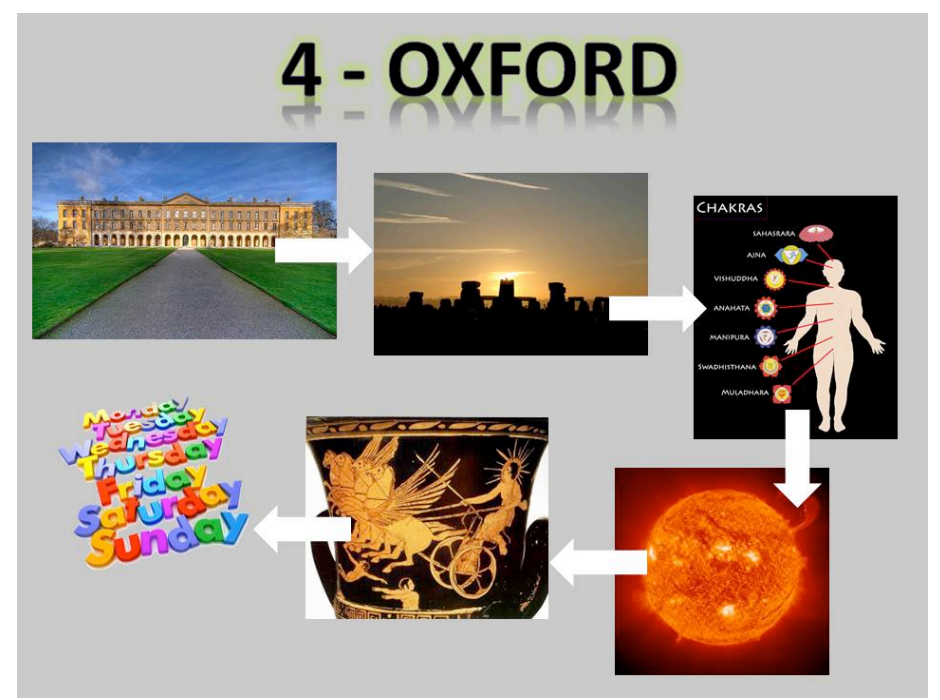

Figure 6. The fourth INSAP was held at Magdalen College, Oxford, in 2003.

\section{INSAP V}

INSAP migrated next to the New World, and was held at the Adler Planetarium in Chicago in 2005. After some concern that the gene pool for the meetings was not growing, and was even stagnating, the fifth meeting brought in a welcome influx of new blood, along with loyal

${ }^{10}$ Christopher Chippindale, Stonehenge Complete (London: Thames and Hudson, 2004). 
repeat visitors. The site was the sparkling shore of Lake Michigan. Chicago is called America's Second City, the Adler is actually the first planetarium in the country and INSAP visited soon after a major renovation. This meeting vaulted INSAP into the twenty-first century, with talks on space art and the use of computers for astronomical visualization and image manipulation. There was an evening event in Millennium Park and John David Mooney hosted the participants for a party at his atelier. INSAP entered its second decade strongly. ${ }^{11}$

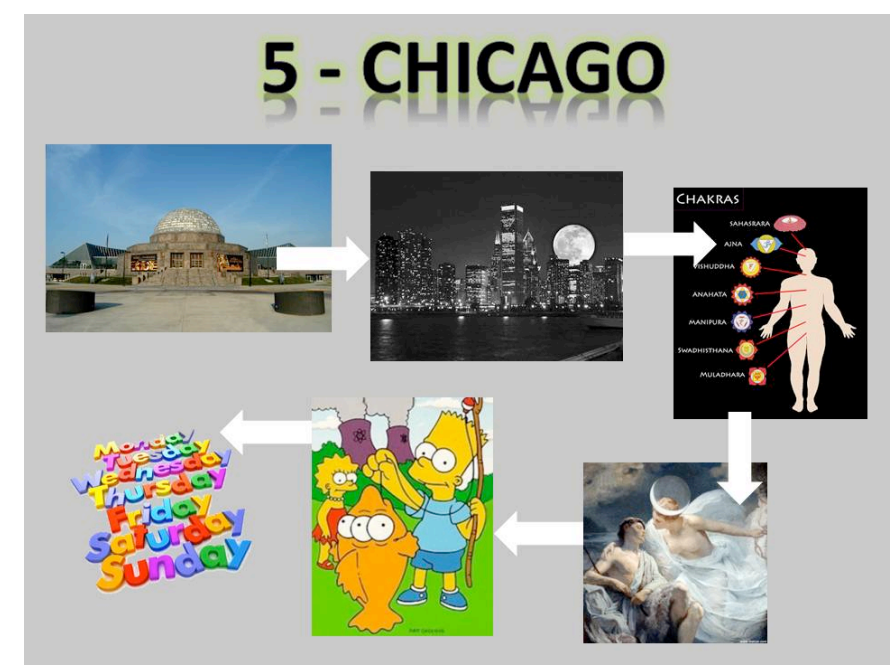

Figure 7. The fifth INSAP was held at the Adler Planetarium in Chicago in 2005 .

One look at the striking pale, slate-grey dome of the Adler Planetarium is enough to be reminded of the Moon. As Monday's child is fair of face, so is the face of Chicago, seen from the promontory where the Adler was built. The associated chakra is the third eye (referenced here by the radiation-mutated three-eyed fish Binky seen in the Simpsons cartoon series); appropriately, for the city that is America's third largest.

\footnotetext{
${ }^{11}$ Marvin Bolt and J. Kaler (eds.), INSAP V, Orem, Utah: Astronomical Society of the Pacific, 2013.
} 


\section{INSAP VI}

Four years passed until the next INSAP meeting, and it moved back close to its starting point in Italy. INSAP VI was timed to coincide with the International Year of Astronomy and the $400^{\text {th }}$ anniversary of Galileo's first use of the telescope for astronomical observations. The setting for this return to astronomy's modern roots was Venice, and the stunning Istituto di Scienze, Lettere ed Arti facing the Grand Canal. The first day of contributions was devoted to Galileo, and participants could walk ten minutes to St. Mark's Square, ascend the campanile, and stand in the spot where Galileo displayed paradigm-shaking sights like the mountains on the Moon and the moons of Jupiter to whoever would believe the evidence of their eyes. The fine arts component of INSAP VI was particularly diverse. Sessions were all well attended, despite the myriad temptations of the surrounding city.

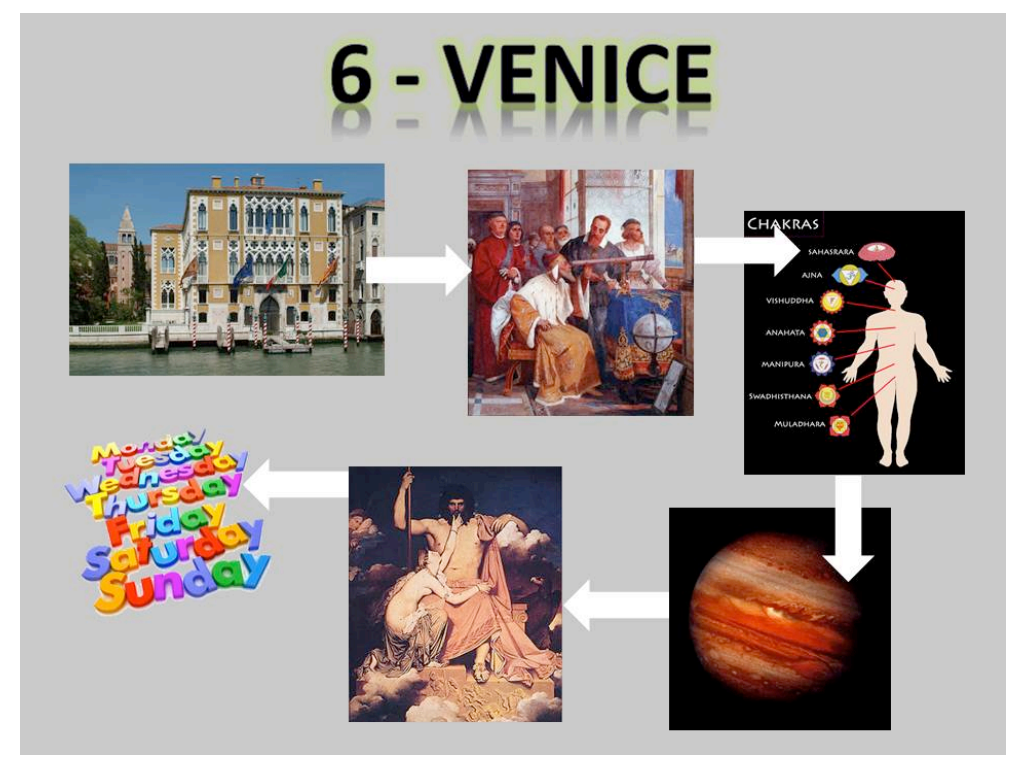

Figure 8. The sixth INSAP was held on the Grand Canal in Venice in 2009.

Galileo's astronomical contributions were so extensive and profoundsunspots, topography of the Moon, phases of Venus, moons of Jupiter, resolution of the Milky Way into the pinpoints of light of individual stars - that it's difficult to pick just one. But his demonstration that the moons of Jupiter engage in miniature versions of the planets' orbits of the 
Sun was a death knell to the Greek idea of crystalline spheres, and the beginning of the 'many worlds' hypothesis: the fact that the Earth is not unique but is one among many geological worlds in the universe. Jupiter is assigned the crown chakra, fitting given Galileo's place at the pinnacle of science. Jupiter gives us Thursday, corresponding to the supreme Greek god Zeus. He was not only the god of sky and thunder, but also the god of order and natural laws, which is a perfect fit to Galileo, who demonstrated the regularity of the heavens.

\section{INSAP VII}

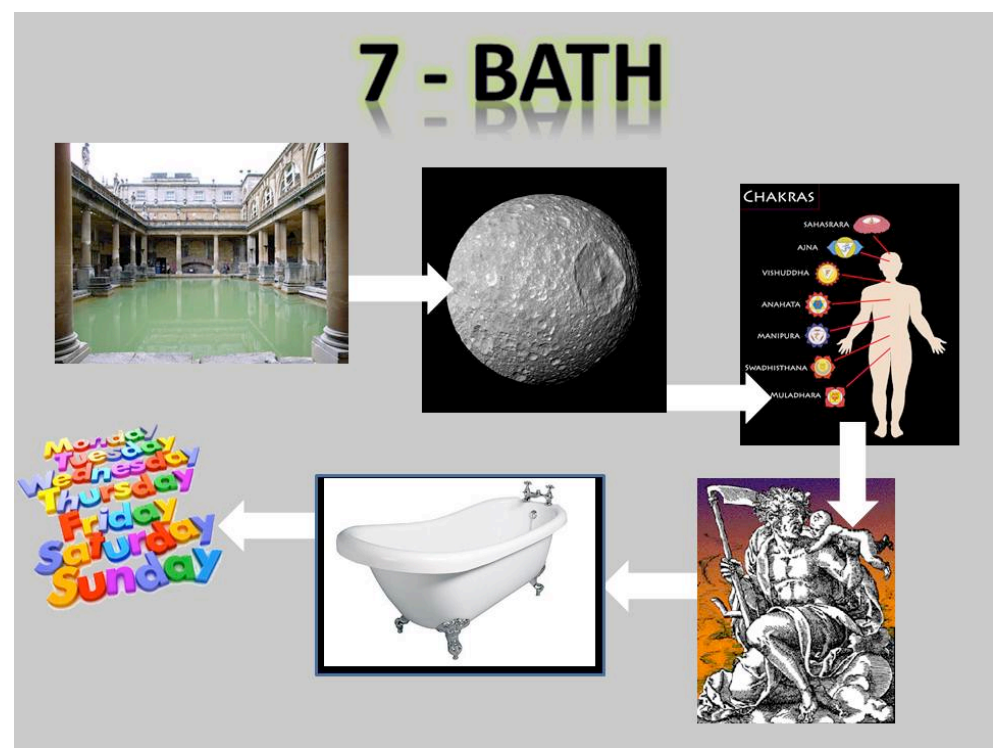

Figure 9.The seventh, and most recent, INSAP was held in Bath in 2010.

And so to the present, where INSAP continues at a breakneck pace; the seventh meeting followed the sixth by barely a year. The latest venue was the Bath Royal Literary and Scientific Institute, in the middle of the elegant Georgian city of Bath in southwest England. William Herschel provided a leitmotiv for the conference, and there was an opening reception at the house where he lived with his sister Caroline and fabricated his telescopes. Participants were treated to the usual rich brew of papers on astronomy, art, and history, with a particular emphasis on the Herschels. William Herschel's seamless pursuit of both astronomy and music is a perfect example of the INSAP ideal. 
In Herschel and Bath, we come full circle in the celestial bodies that mark the week. Herschel is famous for his discovery of Uranus, but there is also a close connection with Saturn: the son of Uranus is Saturn, or Cronos in Greek myth, and one of Herschel's notable discoveries was Mimas, a moon of Saturn and the twelfth largest non-planetary body in the Solar System. ${ }^{12}$ We met Cronos at INSAP I with the violent act that gave rise to Aphrodite: castration of his father with a sickle. The last chakra left to assign is, naturally, the basal chakra.

Rather than end on a violent and dramatic note, we recall the second inspirational element of the seven meetings (apart from Asimov's story): Vincent Van Gogh's painting The Starry Night, which has always featured on INSAP web sites and in promotional material. Van Gogh, who sold only one painting in his short life, did the piece while he was in an asylum in Saint-Remy in 1889. It was presaged by two other paintings that included a star-filled sky: Starry Night over the Rhone, painted in 1888, and Café Terrace at Night, also painted in 1888. The vibrant sky and celestial landscape of The Starry Night, both awesome and overwhelming, remains the best single reference to anyone who asks what INSAP is all about.

I acknowledge the inspiration and friendship of Ray White, not only for the spark he gave to INSAP, but for encouraging me to venture outside the astronomy 'box.' Kudos also to Nick Campion and the Local Organizing Committee for keeping the INSAP tradition strong. This article is missing the musical montages of days and planets that were present in the 'live' version, but those are available on request.

\footnotetext{
${ }^{12}$ M. Lemonick, The Georgian Star: How William and Caroline Herschel Revolutionized our View of the Cosmos (New York: Norton and Company, 2009).
} 